\title{
RESEARCH
}

\section{Dysregulated healing responses in diabetic wounds occur in the early stages postinjury}

\author{
Kiara Boodhoo', Mare Vlok², David L Tabb3,4,5, Kathryn H Myburgh ${ }^{6}$ and Mari van de Vyver(D1 \\ 1Department of Medicine, Faculty of Medicine \& Health Sciences, Stellenbosch University, Cape Town, South Africa \\ ${ }^{2}$ Central Analytical Facility, Proteomics Unit, Stellenbosch University, Cape Town, South Africa \\ ${ }^{3}$ Division of Molecular Biology and Human Genetics, Department of Biomedical Sciences, Stellenbosch University, Cape Town, South Africa \\ ${ }^{4}$ Centre for Bioinformatics and Computational Biology, Stellenbosch University, Stellenbosch, South Africa \\ ${ }^{5}$ Bioinformatics Unit, South African Tuberculosis Bioinformatics Initiative, Stellenbosch University, Cape Town, South Africa \\ ${ }^{6}$ Department of Physiological Sciences, Faculty of Science, Stellenbosch University, Stellenbosch, South Africa
}

Correspondence should be addressed to M van de Vyver: vandevyverm@sun.ac.za

\begin{abstract}
Chronic wounds are a serious and debilitating complication of diabetes. A better understanding of the dysregulated healing responses following injury will provide insight into the optimal time frame for therapeutic intervention. In this study, a direct comparison was done between the healing dynamics and the proteome of acute and obese diabetic wounds on days 2 and 7 following injury. Full thickness excisional wounds were induced on obese diabetic (B6.Cg-lepob/J, ob/ob, $n=14$ ) (blood glucose $423.25 \pm$ $127.92 \mathrm{mg} / \mathrm{dL}$ ) and WT control (C57BL/6J, $n=14$ ) (blood glucose $186.67 \pm 24.5 \mathrm{mg} / \mathrm{dL}$ ) mice. Histological analysis showed no signs of healing in obese DM wounds whereas complete wound closure/re-epithelisation, the formation of granulation tissue and signs of re-vascularisation, was evident in acute wounds on day 7. In obese DM wounds, substance P deficiency and increased MMP-9 activity on day 2 coincided with increased cytokine/chemokine levels within wound fluid. LC-MS/MS identified 906 proteins, of which 23 (Actn3, Itga6, Epb41, Sncg, Nefm, Rsp18, Rsp19, Rpl22, Macroh2a1, Rpn1, Ppib, Snrnp70, Ddx5, Eif3g, Tpt1, FABP5, Cavin1, Stfa1, Stfa3, Cycs, Tkt, Mb, Chmp2a) were differentially expressed in wounded tissue on day $2(P<0.05$; more than two-fold) and 6 (Cfd, Ptms, Hp, Hmga1, Cbx3, Syap1) $(P<0.05$; more than two-fold) on day 7. A large number of dysregulated proteins on day 2 was associated with an inability to progress into the proliferative stage of healing and suggest that early intervention might be pivotal for effective healing outcomes. The proteomic approach highlighted the complexity of obese DM wounds in which the dysregulation involves multiple regulatory pathways and biological processes.
\end{abstract}

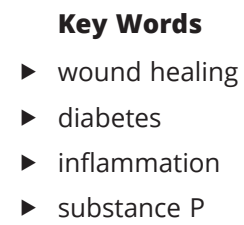

\section{Introduction}

Depending on the underlying cause, chronic wounds are subdivided into three main classes that is, leg ulcers (associated with venous disease), pressure ulcers/ pressure injuries (associated with prolonged bed rest) and diabetic foot ulcers (DFUs) (associated with uncontrolled hyperglycaemia). Of these, DFUs are the most common and very difficult to treat, with standard of care involving debridement, offloading and infection control with amputation often being necessitated. It, therefore, places a socio-economic burden on the patients and enormous 
financial strain on health care systems worldwide (Alexiadou \& Doupis 2012, Frykberg \& Banks 2015, Jones et al. 2019). In 2017, approximately $8.8 \%$ of the world's population was affected by diabetes mellitus (DM) and this percentage is projected to increase to $9.9 \%$ by the year 2045 (Cho et al. 2018). The prevalence of DFUs in DM patients is $4-10 \%$, with a lifetime risk of $25 \%$ and due to the lack of effective treatment strategies, DFUs have a $20-80 \%$ recurrence rate (Mulder et al. 2012, Cho et al. 2018). The mortality rate amongst DFU patients with amputated limbs can be as high as $44 \%$ after 1 year (Fortington et al. 2013). The molecular characterisation associated with impaired/dysfunctional healing responses in pathological conditions has however not yet been fully elucidated (Ganesh \& Ramkumar 2020).

The wound healing process which normally consists of four major phases (haemostasis, inflammation, proliferation and remodelling) (Ozgok Kangal \& Regan 2020) is hindered in DM due to its deviant pathology. The pathogenesis of uncontrolled DM involves persistent hyperglycaemia resulting in the accumulation of advanced glycation end-products (AGEs) (glycosylated proteins and lipids) (Singh et al. 2014). Consequently, oxidative stress (reactive oxygen species, ROS) becomes prominent and a chronic self-perpetuating pro-inflammatory state develops (Goh \& Cooper 2008, Zhong et al. 2017). Together, this toxic microenvironment leads to tissue damage and cellular dysfunction. In DM skin, chronic inflammation together with pathogenesis-induced ischaemia and neuropathy are the leading causes for the development of DFUs (Pradhan et al. 2009, da Silva et al. 2010). DM neuropathy is characterised by insufficient production of neuropeptides such as substance $P$ and the overproduction of endopeptidases such as Neutral endopeptidase (also known as Neprilysin, NEP) and matrix metalloprotease-9 (MMP-9) (Olerud et al. 1999, Antezana et al. 2002, da Silva et al. 2010, Jones et al. 2019). Substance P is secreted by sensory nerves and inflammatory cells (macrophages and eosinophils) upon injury ( $\mathrm{O}^{\prime}$ Connor et al. 2004). It functions via its receptor, neurokinin-1 receptor (NKR-1), and has been shown to promote the wound healing process in both DM and non-DM skin wounds by initiating the acute inflammatory phase of healing (Spenny et al. 2002, Leal et al. 2015). This is thought to occur within the first 3 days postwounding (Leal et al. 2015). Substance $\mathrm{P}$ has also been shown to promote the transition into the proliferative stage of healing by promoting an M2 (pro-regenerative) phenotype in macrophages (Leal et al. 2015). During the proliferative stage of healing, substance P mediates angiogenesis, promotes keratinocyte proliferation and fibrogenesis (Scott et al. 2007, Steyaert et al. 2010, Um et al. 2016). Excessive substance P activity, on the other hand, is associated with hypertrophic scar formation (Scott et al. 2005). In DM skin with underlying neuropathy there is a reduction in the bioavailability of substance $\mathrm{P}$ and an overproduction of the cell surface enzyme, NEP, that degrades substance P (Trengove et al. 1999, Antezana et al. 2002, Spenny et al. 2002, Leal et al. 2015). Although these and other characteristics of chronic wounds are well defined a better understanding of the complex interaction associated with dysregulation that occurs following injury is crucial for the development of more effective treatments. Using fine-tuned animal wound models to identify potential therapeutic targets can bridge the translational gap between laboratory-based and clinical studies (Sabino et al. 2018).

This study compared the healing dynamics as well as the proteome of acute wounds with that of nonhealing diabetic wounds during the initial and late stages following injury. This will provide significant insight into the optimal time frame for therapeutic intervention and aid in identifying critical role players at the different stages postinjury involved in the dysfunctional healing responses.

\section{Materials and methods}

\section{Ethics statement}

This study was approved by the animal research ethics committee (SU-ACUD17-000016) at Stellenbosch University and complied with the South African Animal Protection Act (Act no. 71, 1962). In accordance with the South African National Standards 10386:2008 and the Veterinary and Para-Veterinary Professions Act, 1982, all researchers involved in handling of the animals were authorised by the South African Veterinary Council (SAVC).

\section{Induction of full-thickness excisional wounds and sample collection}

Obese DM mice (B6.Cg-lepob/J, ob/ob, $n=14)(10-12$ weeks; $46.1 \pm 4.2 \mathrm{~g}$ ) (blood glucose $23.49 \pm 7.1 \mathrm{mmol} / \mathrm{L}$ or $423.25 \pm 127.92 \mathrm{mg} / \mathrm{dL})$ and healthy WT control mice (C57BL/6J, $n=14)(10-12$ weeks; $27.3 \pm 3.1 \mathrm{~g})$ (blood glucose $10.36 \pm 1.36 \mathrm{mmol} / \mathrm{L}$ or $186.67 \pm 24.5$ $\mathrm{mg} / \mathrm{dL}$ ) were anaesthetised using Isoflurane gas (Safeline Pharmaceuticals, Cape Town, Western Cape, South Africa). Dorsal hair was shaved, and the skin cleaned with povidone-iodine (Mundipharma, Cape Town, Western 
Cape South Africa) prior to making two identical bilateral full-thickness skin excisions. The procedure included the removal of the underlying panniculus carnosus layer (Chen et al. 2013). Wounds (5 mm diameter) were located $1 \mathrm{~cm}$ below the base of the skull and on either side of the midline. To induce a non-healing obese DM wound, neutral endopeptidase (NEP) $(1.02 \mathrm{mg} / \mu \mathrm{L} ; 150 \mathrm{pmol} / \mathrm{h} / \mu \mathrm{g})$ (SRP6450, Neprilysin/CD10; Sigma-Aldrich) was injected subcutaneously around the wound edges in the ob/ob animals immediately postwounding. The expression of NEP is much greater in the ulcer margins of DFU patients (Antezana et al. 2002) than what is observed in the skin of diabetic animals (delayed healing) and healthy controls (Antezana et al. 2002, Spenny et al. 2002). Exogenous NEP administration into the wound edges of a commonly used diabetic animal model of delayed healing in this study was therefore used to induces a chronic wound that more closely mimic DFUs. Acute wounds were induced on WT control mice (saline injection) as parallel control. Additional control groups included WT control mice with NEP injection $(n=3)$ and streptozotocininduced hyperglycaemic mice (intraperitoneal injection of $50 \mathrm{mg} / \mathrm{kg}$ body weight STZ, 3 days before wounding; blood glucose following STZ-injection $12.1 \pm 0.6 \mathrm{mmol} / \mathrm{L}$ or $217.9 \pm 10.8 \mathrm{mg} / \mathrm{dL})$ with NEP injection $(n=3$ per group). Pain management included the injection of a local anaesthetic, $7 \mathrm{mg} / \mathrm{kg}$ lignocaine (2\%) (Bodene, Port Elizabeth, Eastern Cape, South Africa) immediately postwounding as well as administering $300 \mathrm{mg} / \mathrm{kg}$ acetaminophen (GSK, Cape Town, Western Cape, South Africa) in the drinking water for a period of 3 days.

Wounds were covered by a vapour-permeable PU film (Hydro-film, Paul Hartmann AG, Heidenheim, BadenWürttemberg, Germany) and the accumulated exudate (wound fluid) harvested by needle puncture (Trengove et al. 1999, Schmohl et al. 2012) on day 2 postwounding. After recovery from the anaesthesia, mice were housed individually under standard conditions $(12 \mathrm{~h}$ light: $12 \mathrm{~h}$ darkness cycle at a controlled temperature of $21^{\circ} \mathrm{C}$ ) with ad libitum access to drinking water and chow (Rat and Mouse Breeder Feed, Animal Specialties, Pty, Ltd., Klapmuts, SA) and their appearance and behaviour closely monitored for signs of distress. Following cervical dislocation, wound tissue including a $5 \mathrm{~mm}$ margin was excised. One half of each tissue sample was snap-frozen in liquid nitrogen and stored at $-80^{\circ} \mathrm{C}$ for protein extraction. The other half of each tissue sample was fixed in $10 \%$ buffered formalin solution and embedded in paraffin wax for histological analysis (hematoxylin \& eosin; Masson's Trichrome staining) using standardised techniques.

\section{Assessment of macroscopic wound closure and wound fluid analysis}

Wound images were taken on days 0,2 and 7 using a Canon digital camera (EOS 600D, Canon Inc, Taiwan). The surface area $\left(\mathrm{cm}^{2}\right)$ for each wound and the percentage wound closure was determined using Image $\mathrm{J}$ software (version 1.46, NIH.gov, USA). Wound fluid collected on day 2 was analysed using a Bio-Plex Pro Mouse Cytokine 23-plex assay (M60009RDPD, Bio-Rad) according to the manufacturer's instructions. The cytokines assessed included Eotaxin, granulocyte colony-stimulating factor (G-CSF), granulocyte macrophage colony-stimulating factor (GM-CSF), interferon gamma (IFN $\gamma)$, interleukin (IL)-1 $\alpha$, IL1 $\beta$, IL2, IL3, IL4, IL5, IL6, IL9, IL10, IL12(p40), IL12(p70), IL13, IL17A, keratinocyte chemoattractant (KC), macrophage chemoattractant protein (MCP)-1, macrophage inflammatory protein (MIP)- $1 \alpha$, MIP- $1 \beta$, RANTES and TNF alpha (TNF $\alpha)$. Note: due to the small volume of wound fluid collected from each animal it was necessary to pool the wound fluid from all the animals within each group prior to analysis ( $n=4$ per group).

\section{MMP-9 expression in wounded tissue}

The expression of MMP-9 within the wounded tissue was assessed using a sandwich ELISA kit (AB100732, Abcam) according to the manufacturer's instructions. Snap frozen tissue samples $(100 \mathrm{mg}$ ) were homogenised in liquid nitrogen. Assay buffer $(400 \mu \mathrm{L})$ containing $1 \mathrm{mM}$ phenylmethanesulfonyl fluoride (PMSF) (1083709100, Sigma-Aldrich) and $10 \mu \mathrm{g} / \mathrm{mL}$ Aprotinin (A1153-5MG, Sigma-Aldrich) was added to each sample, incubated on ice $(10 \mathrm{~min})$ and centrifuged at $4^{\circ} \mathrm{C}$ for $10 \mathrm{~min}$ at 12,000 $\boldsymbol{g}$. The protein concentration within the supernatant was determined using a NanoDrop ${ }^{\mathrm{TM}}$ 2000/2000c (Thermo Fisher Scientific) $(260 / 280 \mathrm{~nm})$ and samples stored at $-20^{\circ} \mathrm{C}$. For each sample $6 \mu \mathrm{g}$ of protein was used in the ELISA and the absorbance read at $450 \mathrm{~nm}$ using a micro-plate reader (Multiskan GO 1.00.40, Thermo-Scientific Group).

\section{Immunohistochemistry substance $P$}

Standard immunohistochemistry techniques were used to assess the expression of substance P within the wounded area using a primary anti-substance P antibody (ab10353, Abcam) and an HRP enzyme-conjugated secondary antibody (ab6789, Abcam). Images were taken at $5 \times$ magnification using the Zeiss Axio Vision microscope (Zeiss Axio Observer 7 Inverted microscope, Zeiss). 
The expression of substance $\mathrm{P}$ (\% surface area) was determined using Image J software (version 1.46, NIH. gov, USA).

\section{Histology quantification of healing dynamics}

Tile scan images of H\&E and Masson's Trichrome stained sections were taken at 10x magnification using the Zeiss Axio Vision microscope (Zeiss Axio Observer 7 Inverted microscope, Zeiss). Assessment of the histological parameters such as granulation tissue thickness ( $\mu \mathrm{m})$, epithelial thickness $(\mu \mathrm{m})$, cellularity (nuclei within granulation tissue) (\% surface area) and the number of blood vessels formed within granulation tissue was performed using Image J software (version 1.46, NIH.gov, USA). The histology index was calculated for each wound as indicated in Table 1.

\section{Protein extraction for proteomics}

Homogenised tissue samples (100 $\mathrm{mg}$ ) were incubated in $89 \%$ ethanol containing $50 \mathrm{mM}$ Tris(2-carboxyethyl) phosphine (TCEP; Fluka, Sigma-Aldrich), 1\% acetic acid (Sigma-Aldrich) and $1 \mathrm{mg} / \mathrm{mL}$ caffeine (Pierce) for $1 \mathrm{~h}$ at $4^{\circ} \mathrm{C}$. The supernatant was sonicated in methanol (SigmaAldrich) for $15 \mathrm{~min}$ at $4^{\circ} \mathrm{C}$ and incubated with $600 \mu \mathrm{L}$ of methyl tert-butylether (MTBE; Sigma-Aldrich) for $1 \mathrm{~h}$ at $4^{\circ} \mathrm{C}$. Phase separation was induced by adding $100 \mathrm{mM}$ triethylammonium bicarbonate (TEAB; Sigma-Aldrich) to each sample and centrifugation (14 min at 12,000 g). Four volumes of methanol (Sigma-Aldrich) was added to the lower phase and centrifuged at $12,000 \boldsymbol{g}$ for $10 \mathrm{~min}$. The supernatant was removed, and the pellet was sonicated (10 min at $4^{\circ} \mathrm{C}$ ) with $200 \mu \mathrm{L} 50 \mathrm{mM}$ TEAB pH 7.8 containing 8 $\mathrm{M}$ urea (Sigma-Aldrich), 0.5\% SDS and a protease inhibitor cocktail (Sigma-Aldrich). Four volumes of methanol were added, and samples centrifuged at $12,000 \boldsymbol{g}$ for $10 \mathrm{~min}$. The supernatant was removed, and protein pellet was retained for proteomic analysis. The protein samples underwent an on-bead digestion step followed by a peptide quantification assay (Bradford assay). Samples were resuspended in $50 \mathrm{mM}$ triethyl ammonium bicarbonate (TEAB; Sigma-Aldrich) before reduction with $5 \mathrm{mM}$ triscarboxyethyl phosphine
(TCEP; Fluka, Sigma-Aldrich) $50 \mathrm{mM}$ TEAB for $1 \mathrm{~h}$ at $60^{\circ} \mathrm{C}$. Cystein residues were thiomethylated with $20 \mathrm{mM}$ S-methyl methanethiosulfonate (Sigma-Aldrich) in $50 \mathrm{mM}$ TEAB (Sigma-Aldrich) for $30 \mathrm{~min}$ at room temperature. After thiomethylation the samples were diluted two-fold with binding buffer (100 mM sodium acetate, 30\% acetonitrile, $\mathrm{pH}$ 4.5). The protein solution was added to MagResyn (Resyn Biosciences, Pretoria, Gauteng, South Africa) HILIC magnetic particles prepared according to manufacturer's instructions and incubated overnight at $4^{\circ} \mathrm{C}$. After binding the supernatant was removed and the magnetic particles washed twice with washing buffer (100 mM sodium acetate, $15 \%$ acetonitrile, $\mathrm{pH}$ 4.5). After washing the magnetic particles were suspended in $50 \mathrm{mM}$ TEAB containing trypsin (New England Biolabs, Ipswich, MA, USA) to a final ratio of $1: 10$. After a $6 \mathrm{~h}$ incubation at $37^{\circ} \mathrm{C}$ the peptides were extracted once with $50 \mu \mathrm{L}$ water and once with $50 \%$ acetonitrile (Romil). The samples were dried down and resuspended in $30 \mu \mathrm{L} 2 \%$ acetonitrile:water; 0.1\% FA.

Residual digest reagents were removed using an in-house manufactured C18 stage tip (Empore Octadecyl C18 extraction discs; Supelco). The samples were loaded onto the stage tip after activating the C18 membrane with $30 \mu \mathrm{L}$ methanol (Sigma-Aldrich) and equilibration with 30 $\mu \mathrm{L} 2 \%$ acetonitrile:water; $0.05 \%$ TFA. The bound sample was washed with $30 \mu \mathrm{L} 2 \%$ acetonitrile:water; $0.1 \%$ TFA before elution with $30 \mu \mathrm{L} 50 \%$ acetonitrile:water; 0.05\% TFA. The eluate was evaporated to dryness. The dried peptides were dissolved in 2\% acetonitrile:water; $0.1 \%$ FA for LC-MS analysis. Half the contents if each vial of isobaric Tandem Mass Tag (TMT) (Thermo Fischer Scientific) were added to 14 $\mu \mathrm{g}$ of each sample. The use of 10-plex isobaric labels allowed the relative quantification of proteins by examining all the biological samples from one time point in a single run.

\section{Proteomics liquid chromatography and mass spectrometry}

Liquid chromatography (Dionex nano-RSLC) was performed on a Thermo Scientific Ultimate 3000 RSLC equipped with a $5 \mathrm{~mm} \times 300 \mu \mathrm{m} \mathrm{C}_{18}$ trap column (Thermo

Table 1 Histology index.

\begin{tabular}{l}
\hline Score \\
\hline 1 \\
2 \\
3
\end{tabular}

\section{Description}

Little epidermal and dermal organisation (epithelial thickness < $30 \mu \mathrm{m}$ ); <10 capillary vessels; no granulation tissue formation.

Moderate epidermal and dermal organisation (epithelial thickness <100 $\mu \mathrm{m}$ ), few newly formed capillary vessels evident, cellular infiltration; granulation tissue thickness (>100 $\mu \mathrm{m})$.

Complete remodelling of the epidermis and dermis, well-formed capillary vessels.

Scoring parameters were adapted from Galeano et al. (2001). 
Scientific) and a nanoEase M/Z Peptide CSH $25 \mathrm{~cm} \times 75$ $\mu \mathrm{m} 1.7 \mu \mathrm{m}$ particle size $\mathrm{C}_{18}$ column (Waters, Milford, Massachusetts, USA) analytical column. Chromatography was performed at $45^{\circ} \mathrm{C}$ and the outflow delivered to the mass spectrometer (Thermo Scientific Fusion, Nanospray Flex ionisation source) through a stainless-steel nano-bore emitter. MS1 scans were performed using the orbitrap detector set at 120,000 resolution over the scan range 350-1500 with AGC target at 4E5 and maximum injection time of $50 \mathrm{~ms}$. MS2 acquisitions were performed using monoisotopic precursor selection for ion with charges $+2-+7$ with error tolerance set to $\pm 10 \mathrm{ppm}$. Fragment ions were detected in the orbitrap mass analyser set to 50,000 resolution with the AGC target set to 5E4 and the maximum injection time to $80 \mathrm{~ms}$.

\section{Statistical analysis}

Statistical analysis was performed using GraphPad Prism (version 8.2.0). The normal distribution of data was determined using the Shapiro-Wilk and Kolmogorov-Smirnov test. Data are presented as mean \pm S.D. Two-way ANOVAs with Tukey post hoc tests were performed to determine the effect of time, group and group $\times$ time. Welch's T-test with two-tailed $P$ value was used for comparison of the healing dynamics and proteome between the acute and DM wounds. Level of significance was accepted at $P<0.05$. $P$ values were multiple testing corrected via the Benjamini-Hochberg FDR procedure to obtain Q-values. Functional pathway analysis and protein interactions were mapped for the differential proteins of interest $(P<0.05)$ (identified through biostatistical analysis of the LC-MS/MS data) using STRING (version 11.0, string-db.org).

\section{Results}

\section{Animal wellness}

All animals tolerated the procedure well with a 100\% survival rate observed for a period of 7 days postwounding. Refer to Fig. 1A for representative images illustrating macroscopic wound size on days 0 and 7 in the respective groups. For both the WT saline (body weight $27.3 \pm 3.1 \mathrm{~g}$ ) and obese DM (body weight $46.1 \pm 4.2 \mathrm{~g}$ ) wounded animals. an initial drop in body weight of approximately $3 \mathrm{~g}$ (WT $12 \%$ decrease $(P=0.0011)$; obese DM $4-6 \%$ decrease), were observed during the first 2 days postwounding. The animals did, however, recovered from this initial weight loss
A

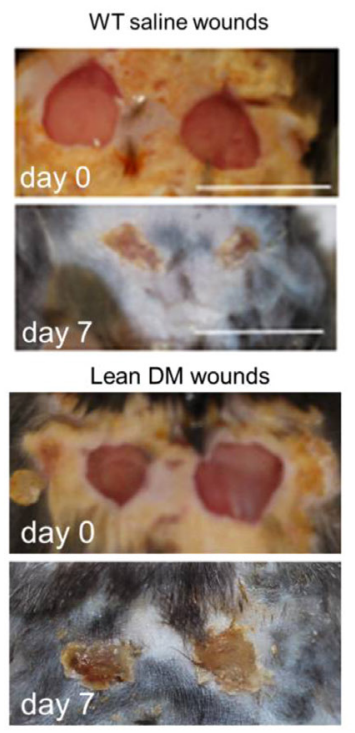

WT wounds

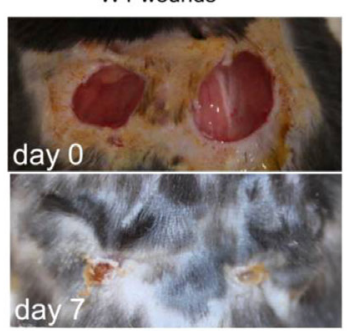

Obese DM wounds
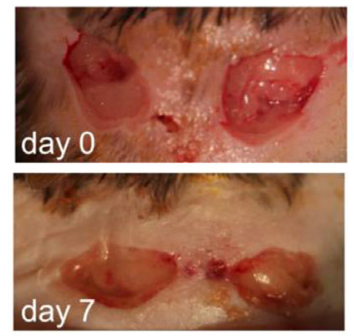
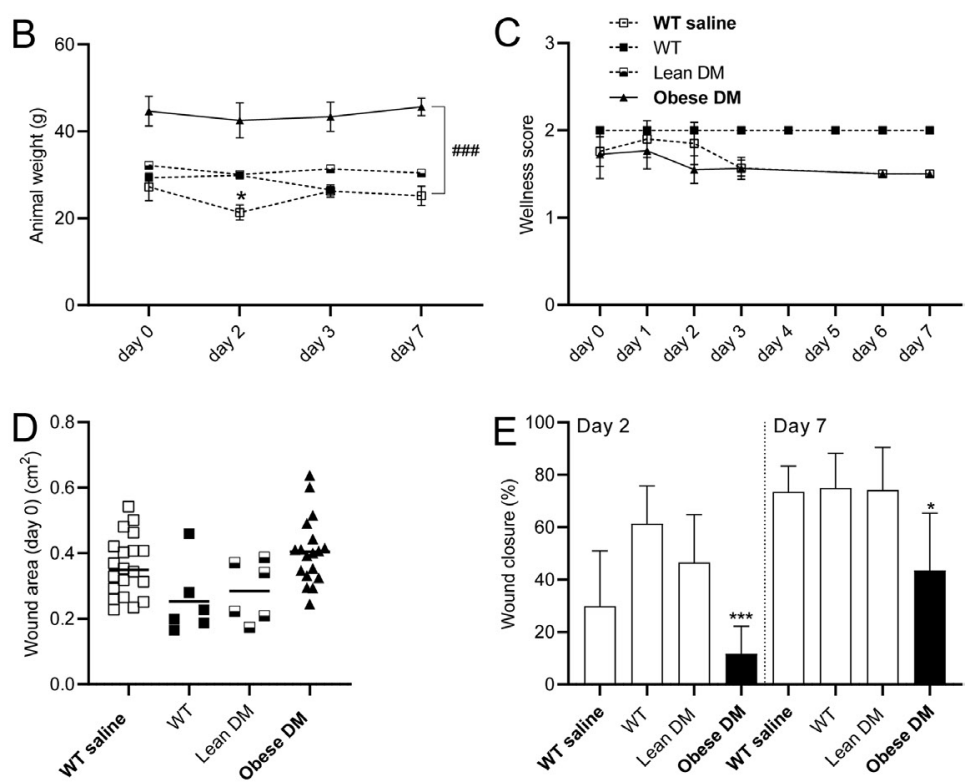

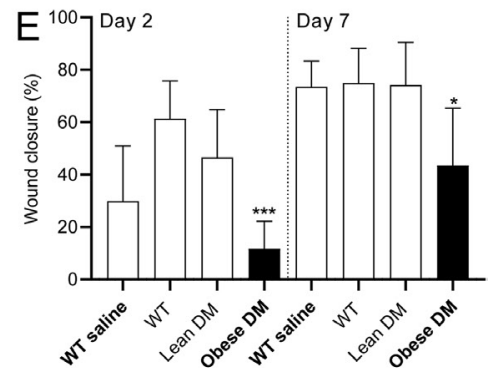

\section{Figure 1}

Animal wellness. (A) Representative images of wounds on days 0 and 7 postwounding induced in the following animal models: WT mice + saline injection (WT saline wounds); WT mice + NEP injection (WT wounds); streptozytocin-induced hyperglyceamia in WT mice + NEP injection (lean DM wounds); ob/ob mice + NEP injection (obese DM wounds). (B) Animal weight (g) over time postwounding. (C) Animal wellness behaviour score over time postwounding with 1 = alert, curious, active, normal movement; 2 = less active, less responsive, abnormal movement; 3 = inactive, poorly responsive. (D) Comparison of wound size $\left(\mathrm{cm}^{2}\right)$ on day 0 immediately postwounding. (E) Percentage wound closure (\%) in acute DM wounds on days 2 and 7 postwounding. Statistical analysis: Two-way ANOVA with Tukey post hoc test. $* P<0.05$ indicates a significant difference from day 0 within the same group and \#\#\#P<0.001 indicates significant difference between groups (B, C, D and E). ${ }^{*} P<0.05$ and $* * * P<0.001$ indicate significant difference between groups ( $D$ and $\left.E\right)$. A full colour version of this figure is available at https://doi.org/10.1530/JME-20-0256. 
(weight day 7; WT $25.2 \pm 0.9$ g, obese DM $45.6 \pm 0.9$ g) (Fig. 1B). The body weight for the WT+NEP $(29.9 \pm 2.4 \mathrm{~g})$ and lean DM+NEP $(32.2 \pm 0.7 \mathrm{~g})$ groups remained stable throughout the study (Fig. 1B). There were no differences evident in the wellness scores (behaviour) of animals (Fig. 1C).

\section{Wound healing dynamics}

To identify the most appropriate model representative of acute and non-healing diabetic wounds, macroscopic wound closure was compared between treatment groups. At 7 days postwounding there was no significant difference in wound closure evident between the WT saline (73.5 \pm 9.7\%), WT+NEP $(74.9 \pm 13.2 \%)$ and STZ-injected WT+NEP $(74.2 \pm 16.3 \%)$ groups, whereas healing was significantly delayed in obese DM wounds $(43.5 \pm 21.9 \%)$
(Fig. 1A and E). For all subsequent analysis, the WT saline wounds were chosen to represent acute wounds and the obese DM wounds were chosen to represent non-healing diabetic wounds. Immediately postwounding on day 0 , there was no difference in wound size (WT $0.359 \pm 0.021$ $\mathrm{cm}^{2}$, obese DM $0.424 \pm 0.017 \mathrm{~cm}^{2}$ ) between the acute and obese DM groups (Fig. 1D). In the acute wounds, significant wound closure and re-epithelisation was evident (day 2: $29.9 \pm 6.7 \%$; day $7: 73.5 \pm 3.1 \%$ ) postwounding, whereas obese DM wounds remained open (day 2: $11.7 \pm 3.7 \%$; day 7: $43.5 \pm 6.9 \%)$ with no epithelisation evident $(P=0.008)$ (Fig. 1A and E). This was confirmed using histological assessment of healing dynamics (Fig. 2A and B). On day 7 postwounding, significant granulation tissue formation (thickness $1015 \pm 177 \mu \mathrm{m}$ ) was evident in acute wounds whereas none had formed in the obese DM wounds $(P<0.01)$ (Fig. $2 \mathrm{~A}$ and B). Within the granulation
A
09
0
5
0
3
0
50
0
4
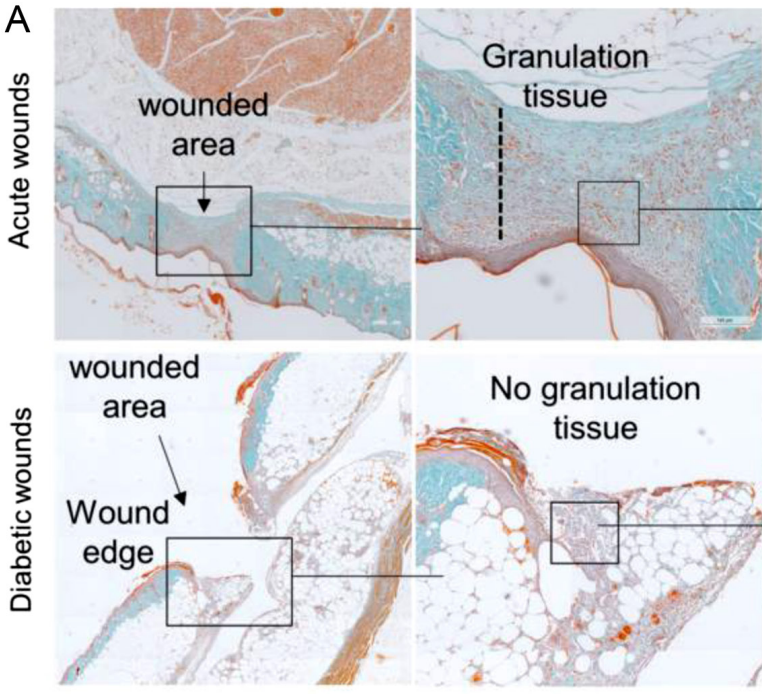

B
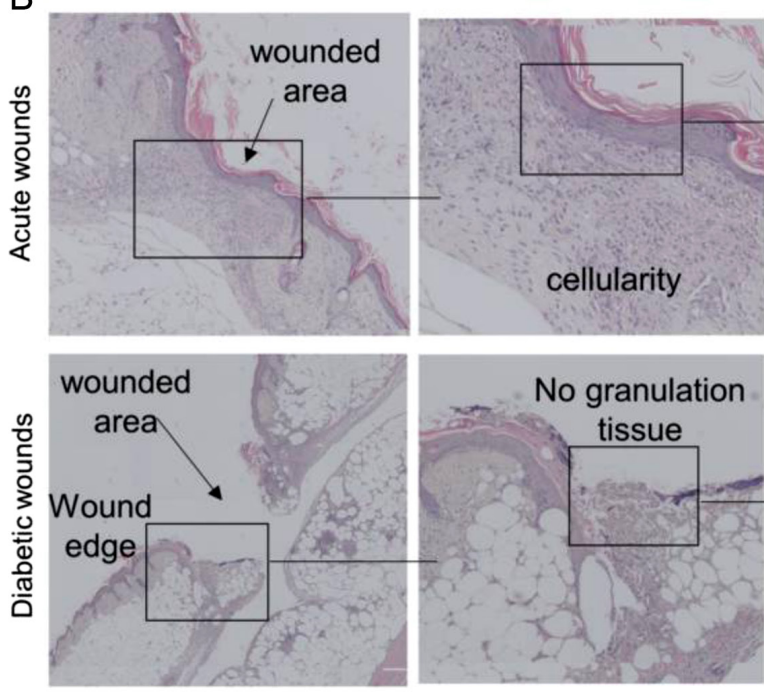
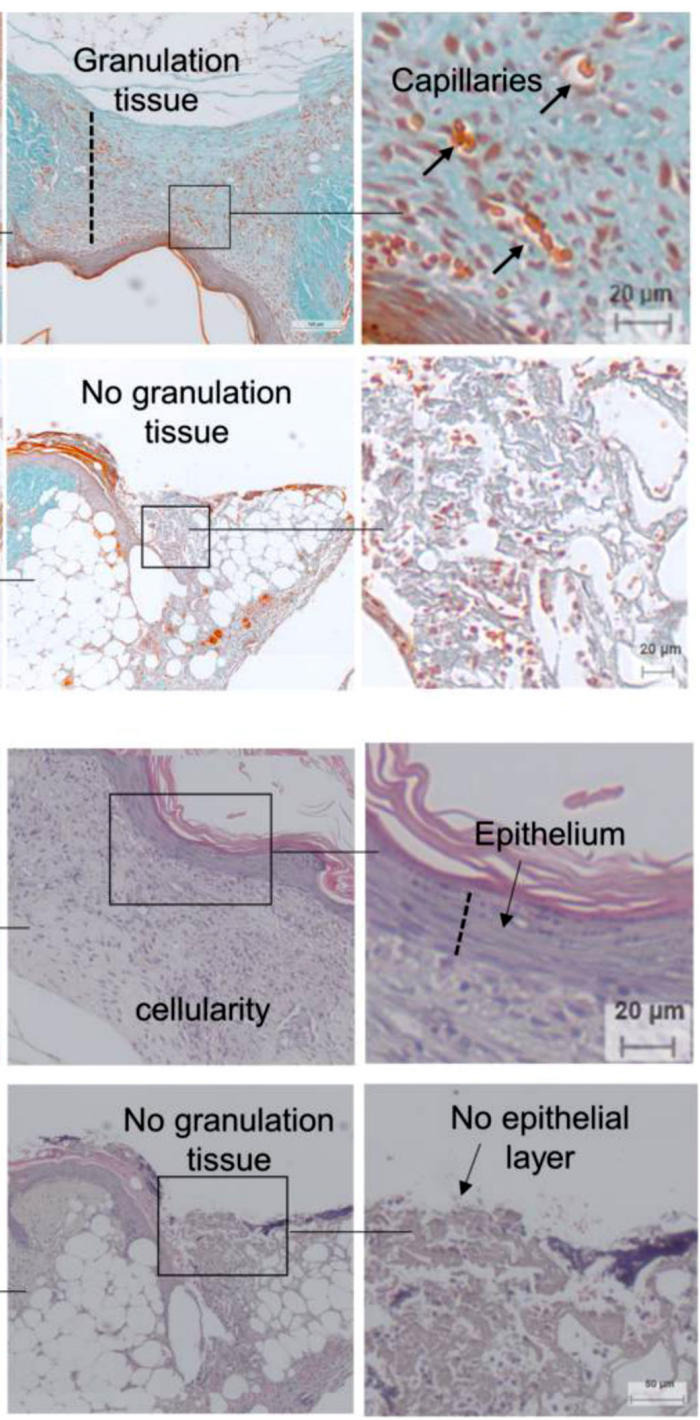

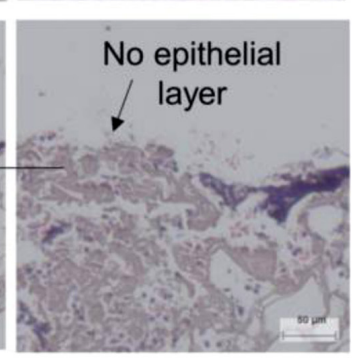

\section{Figure 2}

Histological comparison of acute and obese diabetic (DM) wounds. (A) Massons Trichrome staining. Representative images illustrating the wound area and wound edges, the formation of granulation tissue and the structural organisation within the wounded area on day 7 postwounding. Dotted line (---) indicates granulation tissue thickness. Arrows indicate capillaries. (B) Hematoxylin \& eosin staining. Representative images illustrating the wound area and wound edges, the presence of cell nuclei (blue/purple) within granulation tissue and the epithelial layer. Dotted line (---) indicates the thickness of the newly formed epithelium. A full colour version of this figure is available at https://doi.org/10.1530/ JME-20-0256. 
tissue, cellularity was evident with nuclei representing $11.4 \pm 1.1 \%$ of the surface area and newly formed capillaries were clearly visible in the acutely wounded areas (Fig. 2A and B). Quantification of the histological parameters indicated that acute wounds had an overall histological score of $2 \pm 1$ whereas obese DM wounds had a score of $1 \pm 0$ on day 7 postwounding with no signs of healing (Table 1).

\section{Substance P and MMP-9}

A significant difference was evident between groups with regards to the expression of both MMP-9 and substance $\mathrm{P}$ within the wounded area (Fig. 3). Despite variability in the expression of MMP-9 within the obese DM wounds, on day 2 postwounding, MMP-9 levels were four- to eight-fold higher in obese DM compared to acute wounds $(P=0.0297)$ and remained slightly elevated on day 7 $(P=0.05)$ (Fig. 3A). Immunohistochemistry illustrated a deficiency in the expression of substance $P$ in the obese DM wounds immediately postwounding (acute $8.7 \pm 3.3 \%$; DM $1.5 \pm 2.3 \%)(P<0.05)$ as well as on day 2 (acute $19.3 \pm 8.8 \%$; DM $4.8 \pm 2.6 \%)(P<0.05)$ (Fig. 3B and C). Refer to Fig. $3 \mathrm{C}$ for representative images illustrating substance P expression within the wounded areas at each of the respective time points.

\section{Cytokine profile in wound fluid}

On day 2 postwounding, the level of pro-inflammatory cytokines, chemokines and anti-inflammatory cytokines within the pooled wound fluid samples were overall higher in the obese DM compared to acute wounds as illustrated in Fig. 4. All of the chemokines assessed were overexpressed with GCSF (acute $516.65 \mathrm{pg} / \mathrm{mL}$; DM 5199.68 $\mathrm{pg} / \mathrm{mL}$ ), KC (acute $89.75 \mathrm{pg} / \mathrm{mL}$; DM $1258.26 \mathrm{pg} / \mathrm{mL}$ ), MCP1 (acute 166.46 pg/mL; DM 5857.79 pg/mL), MIP1 $\alpha$ (acute $82.12 \mathrm{pg} / \mathrm{mL} ; \mathrm{DM} 435.79 \mathrm{pg} / \mathrm{mL}$ ) and MIP1 $\beta$ (acute $139.19 \mathrm{pg} / \mathrm{mL}$; DM $554.89 \mathrm{pg} / \mathrm{mL}$ ) being the most prominent in obese DM wound fluid. Similarly, the proinflammatory cytokines IL1 $\alpha$ (acute $28.19 \mathrm{pg} / \mathrm{mL}$; DM $219.04 \mathrm{pg} / \mathrm{mL}$ ), IL6 (acute $95.54 \mathrm{pg} / \mathrm{mL}$; DM $873.31 \mathrm{pg} / \mathrm{mL}$ ), IL12(p40) (acute $18.92 \mathrm{pg} / \mathrm{mL} ; \quad \mathrm{DM} 44.71 \mathrm{pg} / \mathrm{mL}$ ), IL12(p70) (acute 10.53 pg/mL; DM $96.87 \mathrm{pg} / \mathrm{mL}$ ), RANTES (acute $0 \mathrm{pg} / \mathrm{mL} ; \mathrm{DM} 72.73 \mathrm{pg} / \mathrm{mL}$ ) and TNF $\alpha$ (acute 8.87 $\mathrm{pg} / \mathrm{mL}$; DM $56.04 \mathrm{pg} / \mathrm{mL}$ ) were prominent in obese $\mathrm{DM}$ wound fluid. In comparison, the expression levels of anti-inflammatory cytokines were relatively low in the obese DM wounds Fig. 4.
A

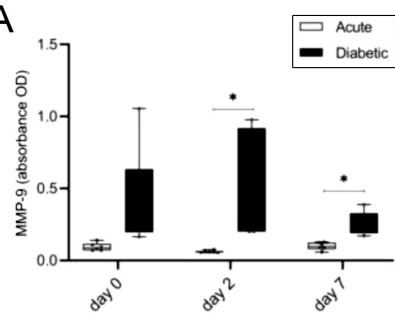

C Acute wounds
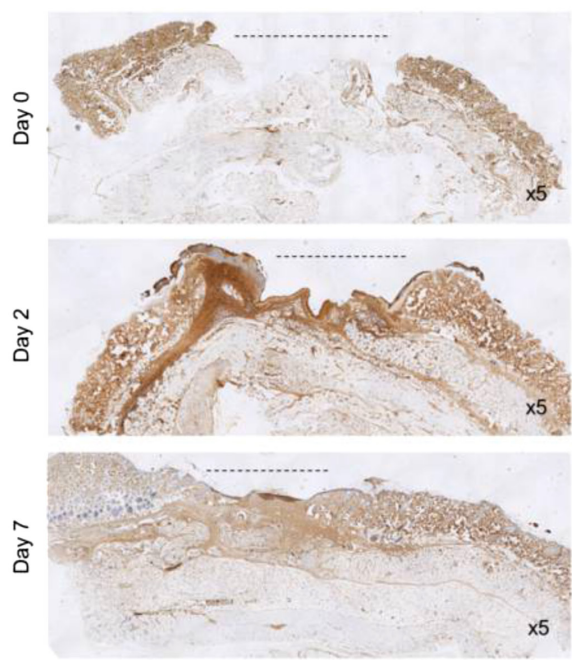

$x 5$
B

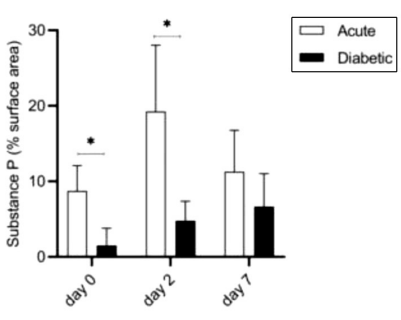

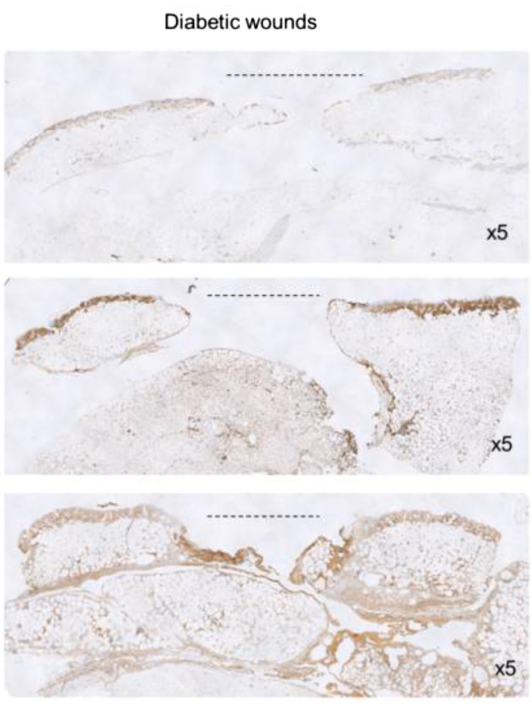

Figure 3

MMP-9 and substance $P$ expression within acute and obese diabetic (DM) wounds. (A) MMP-9 expression (absorbance) in acute and DM wounds on days 0,2 and 7 postwounding. (B) Substance $P$ (\% surface area) expression levels in acute and DM wounds on days 0, 2 and 7 postwounding. (C) Representative images illustrating substance $P$ expression. Dotted line (---) indicates the wounded area. Statistical Analysis: Two-way ANOVA with Tukey post hoc test. $* P<0.05$ indicates the significant difference between groups at the same time point. A full colour version of this figure is available at https://doi. org/10.1530/JME-20-0256. 

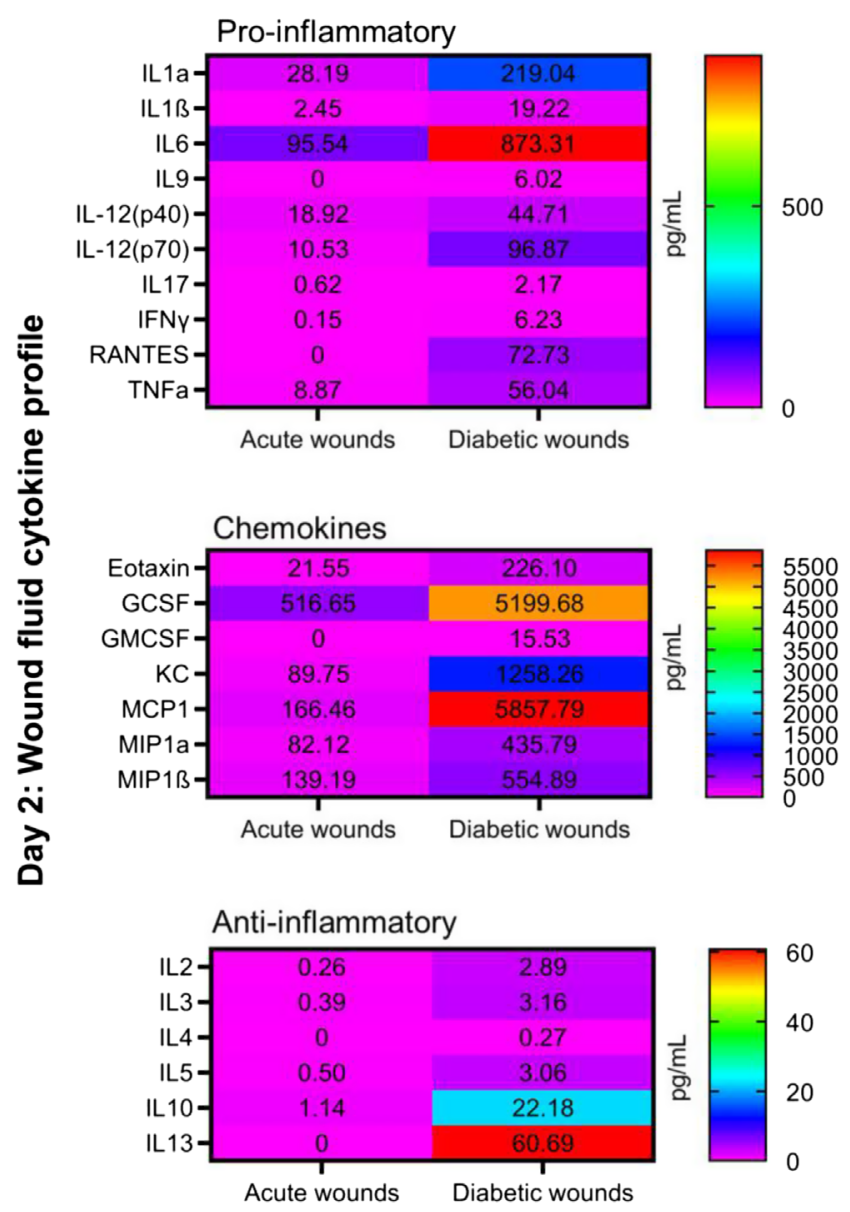

\section{Figure 4}

Cytokine profile within wound fluid derived from either acute or obese diabetic (DM) wounds. Heat map illustration the levels ( $\mathrm{pg} / \mathrm{mL}$ ) of proinflammatory cytokines, chemokines and anti-inflammatory cytokines in acute and DM wounds. Note: due to the small volume of wound fluid collected from each animal it was necessary to pool the wound fluid from all the animals within each group prior to analysis ( $n=4$ per group). A full colour version of this figure is available at https://doi.org/10.1530/JME-20-0256.

\section{Proteome}

A total of 906 proteins with each more than three unique peptides were identified (Fig. 5). On day 2 postwounding, 135 differentially expressed proteins $(P<0.05)$ were observed between acute and chronic wounds (Fig. 5A and B) with a prominent cluster of ribosomal protein-interactions evident. Of these 135 proteins, 20 were upregulated more than two-fold and 3 were downregulated (>two-fold) in chronic wounds (Fig. 5C and Table 2). Functional grouping indicated that the dysregulated proteins of interest on day 2 were involved in either structural integrity (Actn3, Itga6, Epb41), the neurofilament network (Sncg, Nefm), ribosomal function/ transcriptional translation or protein modification
(Rsp18, Rsp19, Rpl22, Macroh2a1, Rpn1, Ppib, Snrnp70, Ddx5, Eif3g), cellular growth (Tpt1), metabolic regulation/ lipid rafts (FABP5, Cavin1), co-factors/catalases/protease inhibitors (Stfa1, Stfa3, Cycs, Tkt), oxygen transport $(\mathrm{Mb})$ or vestibular bodies (Chmp2a) (Table 2). On day 7 postwounding, 35 proteins were differentially expressed $(P<0.05)$ between acute and chronic wounds with only two upregulated and four downregulated more than twofold (Fig. 5D, E and F). The functional grouping indicated that the dysregulated proteins of interest on day 7 were involved in either immune modulation (Cfd, Ptms, $\mathrm{Hp}$ ), transcriptional regulation (Hmga1, Cbx3) or neural synapses (syap1). The relative expression levels, as well as the $P$-values for the identified proteins that were either upregulated or downregulated more than two-fold in the obese DM compared to acute wounds at the respective time points, are presented in Table 2 .

\section{Discussion}

Wound repair is highly complex, comprising a series of coordinated and overlapping processes. Impaired healing is one of the most serious and debilitating complications of DM, yet current treatments are far from optimal (Sen et al. 2009). A better understanding of the complex nature of chronic DM wounds and the dysregulation that occurs at specific stages postwounding is crucial for the development of more effective treatments. A direct comparison of acute and obese DM wounds in the current study clearly illustrates that extensive dysregulation in the healing responses occur within the first 2 days postinjury suggesting that early intervention might be pivotal for effective healing outcomes and to potentially limit the reoccurrence of wounds. Taken together, the data from the current study is consistent with previous observations indicating that the chronic DM wounds have an inability to progress through the normal phases of healing into the proliferative stage (Landén et al. 2016). This was evident in both macroscopic and protein level. Histological analysis showed no signs of healing within the obese DM wounds even after 7 days, whereas complete wound closure/re-epithelisation, the formation of granulation tissue and signs of re-vascularisation was evident in acute wounds. During the early stage postinjury, deficiency in substance $\mathrm{P}$ expression and increased protease activity (MMP-9) within the wounded tissues coincided with excessive levels of chemokines and pro-inflammatory cytokines, known to attract phagocytic immune cells, in the wound 
A Intensity Fractions: Day 2

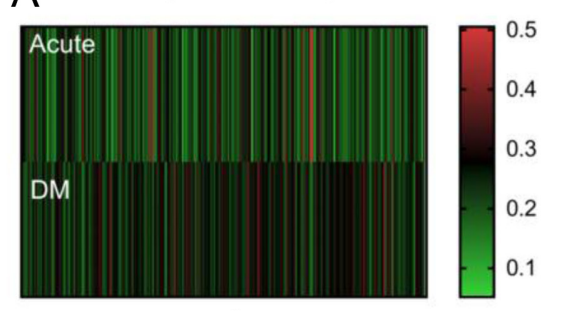

C

$\mathrm{F}$

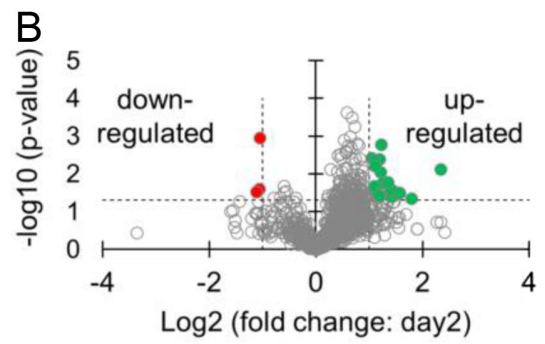

Log2 (fold change: day2)
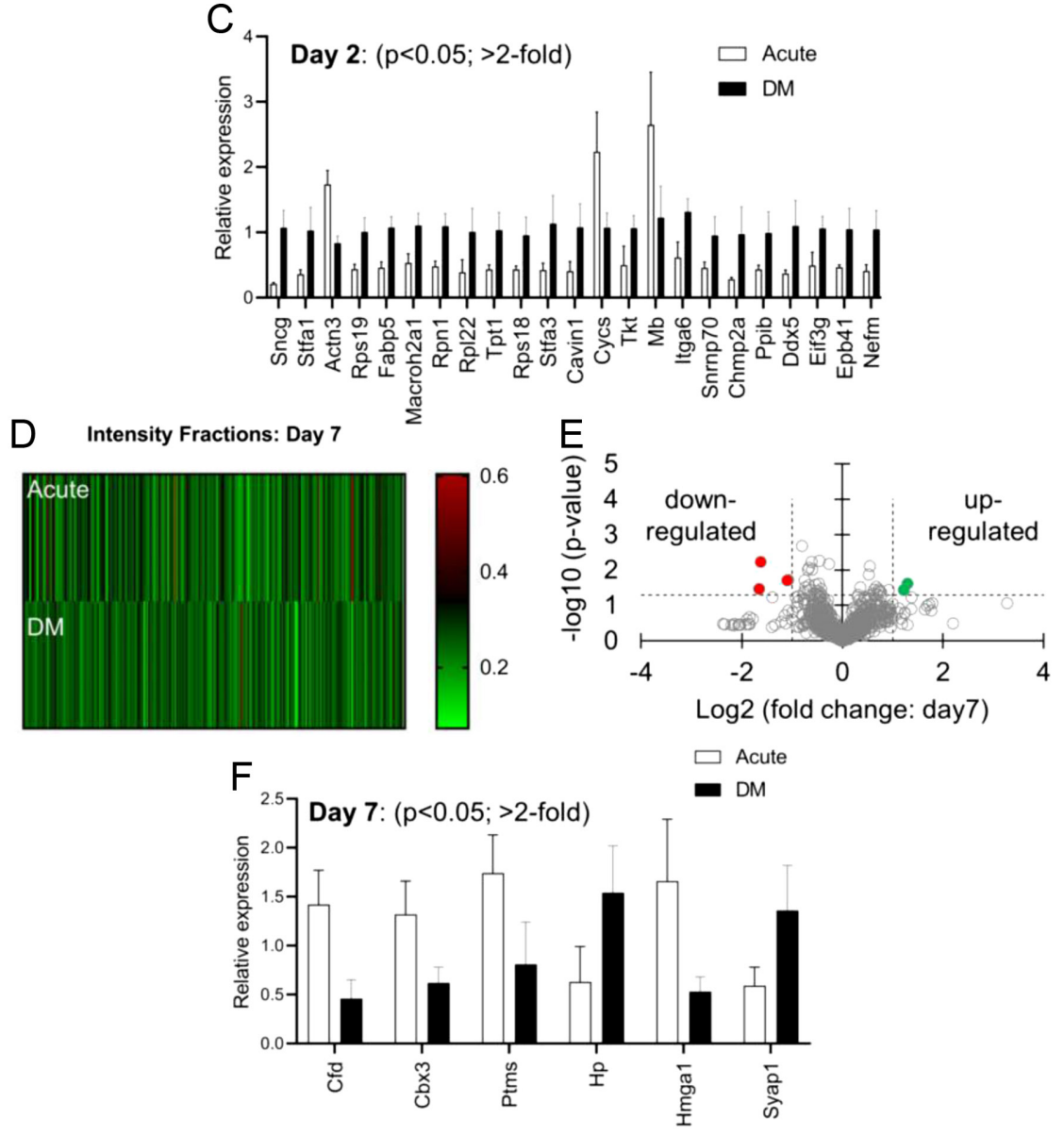

\section{Figure 5}

Proteome comparison of acute $(n=4)$ and diabetic (DM) $(n=4)$ wounds. (A and D) Heatmap indicating the maximum intensity projection of the 906 proteins detected at the respective time points. (B and $E$ ) Volcano plots indicating the differentially expressed proteins of interest $(P<0.05)$ as well as the number of proteins that were either up(green) or downregulated (red) more than two-fold in the DM vs acute wounds on day 2 (B) and day 7 (E), respectively. ( $C$ and F) Relative expression levels of the differentially expressed proteins of interest ( $P<0.05$; more than two-fold) identified on day 2 (B) and day 7 (D) postwounding. A full colour version of this figure is available at https:// doi.org/10.1530/JME-20-0256. fluid derived from DM wounds. This is consistent with observations from (Fadini et al. 2016) indicating that phagocytic neutrophil associated NETosis is involved in delayed DFU healing. A substantially larger number of dysregulated proteins were furthermore identified in the early stage (day 2) compared to the later stage of healing (day 7) confirming the importance of the initial response in predicting outcome. The proteomic comparison at different stages postwounding furthermore enabled the novel identification of proteins potentially involved in the dysregulated healing responses. These proteins and their known roles in either wound healing-associated processes or diabetes will be discussed based on functional grouping at either the initial (2 days) or late stages (7 days) postwounding.
Initial stages structural proteins (Itga6, Epb41, Actn3)

Integrins have an important function in cell-cell and cellmatrix adhesions and have been shown to play a crucial role in angiogenesis, matrix remodelling and epithelial/ fibroblast/keratinocyte migration (Chen et al. 2001, Mercurio et al. 2001, Grose et al. 2002, Desai et al. 2013). The specific $\alpha 6$ subunit has been identified as a candidate gene in high-fat diet-induced DM (Kobayashi et al. 2014) and its expression is altered in various DM comorbidities such as retinopathy (Robbins et al. 1994), neuropathy (Guo et al. 2019) and nephropathy (Jin etal. 1996). Of specific relevance to wound healing is the role of integrin $\alpha 6$ in angiogenesis and fibroblast senescence (Jun \& Lau 2010, 2017). 


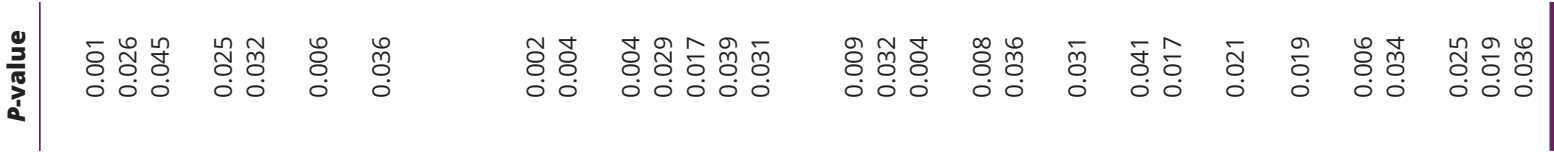

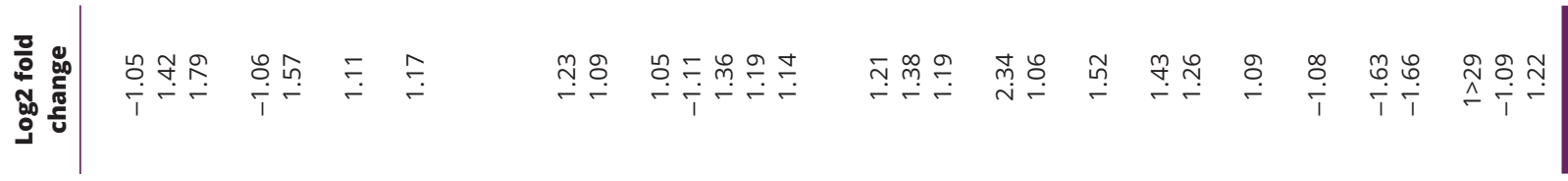

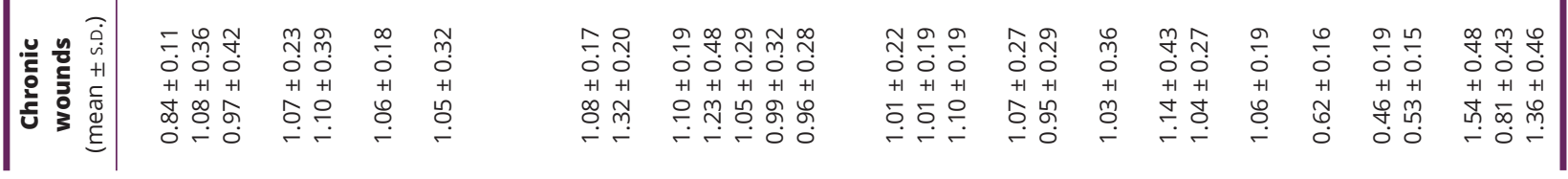

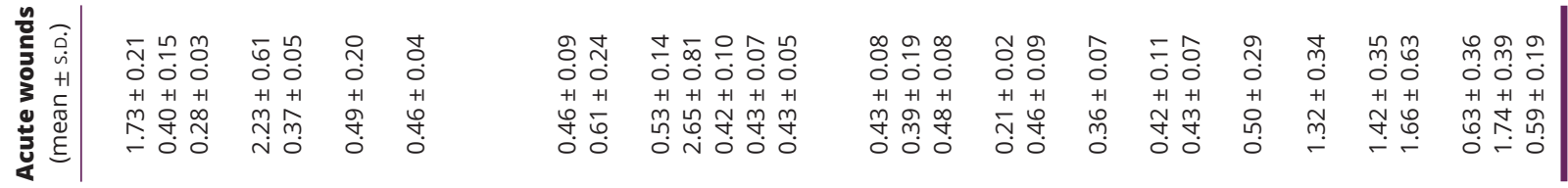

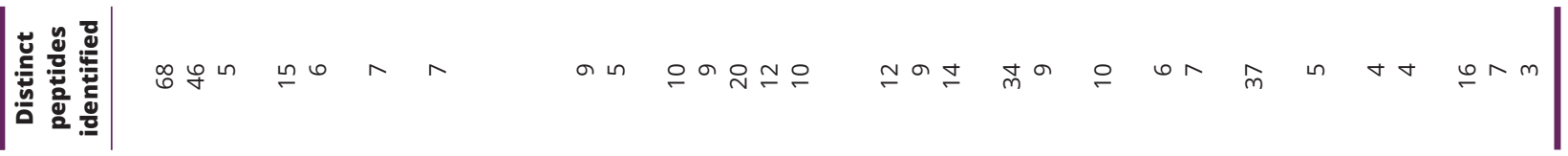

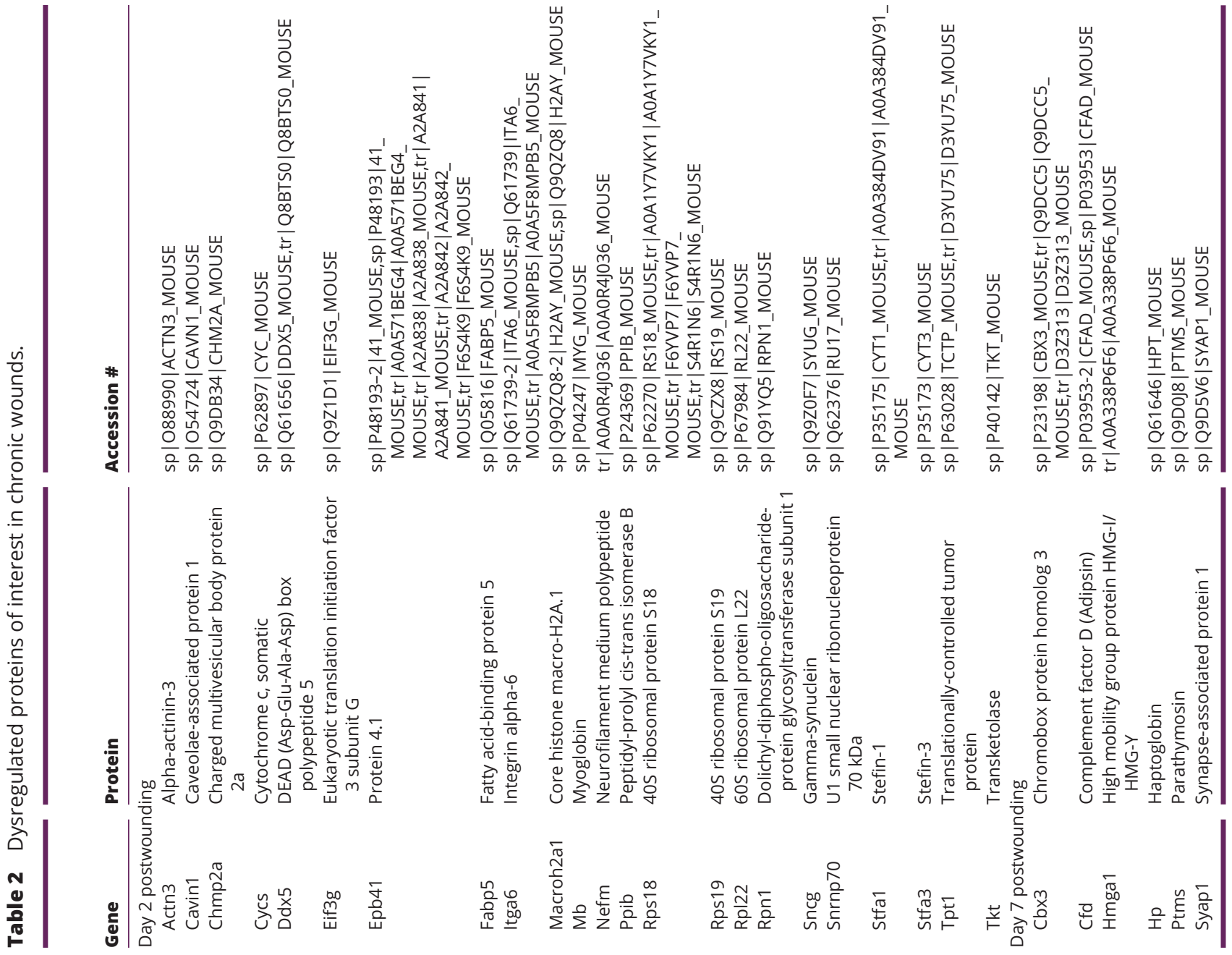


Jun and Lau (2017) demonstrated that the fibrosis associated gene, Ccn2 induce fibroblast senescence through integrin $\alpha 6 \beta 1$-mediated accumulation of ROS that in turn activates p53 signalling. The senescent-associated secretory phenotype (SASP) in fibroblasts, in turn, upregulates the expression of MMPs and downregulate collagen production, which restricts fibrosis in normal cutaneous wound healing (Jun \& Lau 2010), but excessive signalling could hamper regeneration as was evident in the DM wounds. During angiogenesis, integrin $\alpha 6$ heterodimeriSe with the $\beta 1 / 4$ subunit to regulate endothelial cell-matrix interactions. In functional angiogenesis, integrin $\alpha 6$ must be downregulated during the early stages but is essential for vessel maturation during the later stages and is therefore dynamically regulated (Desai et al. 2013). In the current study, integrin $\alpha 6$ was overexpressed during the initial stages postwounding and could potentially be implicated in the lack of revascularisation in DM wounds. Although cause-effect could not be established in the current study, the role of integrin $\alpha 6$ dysregulation in impaired healing is supported by the observations from Desai et al. (2013).

The two other structural proteins identified in this study include Protein 4.1 (Epb41) and alpha-actinin 3 (Actn3), neither of which have been studied in the context of either DM nor wound healing. Epb41 plays a role in intracellular signal transduction with very little additional data available. Actn3 mediates the interaction between cytoskeletal proteins and the sarcomeres (Z-line) within skeletal muscle (Hsu et al. 2018). It is known to affect skeletal muscle function and glycogen metabolism with deficiency linked to a loss of force generation and increased susceptibility to damage (Seto et al. 2011). This protein has been mainly studied in the context of sports performance and muscular pathologies, with only one study showing a link between Actn3 and insulin resistance (Mason et al. 2011). In chronic DM wounds (involving the underlying muscle layer), Actn3 is, therefore, most likely involved in cytoskeletal disorganisation and altered glycogen metabolism.

\section{Initial stages neurofilament proteins (Sncg, Nefm)}

Two proteins involved in the neurofilament network integrity and synaptic transmission, namely gamma synuclein (Sncg) and neurofilament medium polypeptide (Nefm) were differentially expressed in the acute and DM wounds in this study. Even though Sncg is considered a neuropeptide (peripheral neurons) it is also highly expressed in white adipose tissue (WAT), (Oort et al. 2008) and share functional links with leptin and fatty acid-binding protein 4 (Oort et al. 2008, Bag et al. 2015, Dunn et al. 2015). Its prominent role in lipid metabolism was confirmed in a study indicating that Sncg knockout mice are protected against high-fat diet-induced metabolic complications (Millership et al. 2012). The increased levels of Sncg detected in the DM wounds in the current study is thus likely related to the abundance of WAT within the wound edges. The overexpression of Nefm in the DM wounds is, however, consistent with observations from a streptozotocin-induced DM rat model, in which the accumulation of the Nefh and Nefm subunits in proximal axons was suggested to be contributing factors in nerve degeneration leading to DM neuropathy (Sayers et al. 2003).

\section{Initial stages proteins involved in ribosomal function, transcriptional translation or protein modification (Rsp18, Rsp19, Rpl22, Macroh2a1, Rpn1, Ppib, Snrnp70, Ddx5, Eif3g)}

In the DM wounds, a large cluster of ribosomal-interacting proteins were differentially expressed, of which nine proteins (Rsp18, Rsp19, Rpl22, Macroh2a1, Rpn1, Ppib, Snrnp70, Ddx5, Eif3g) were upregulated more than twofold on day 2 postwounding. Ribosomal proteins are RNAbinding proteins that function in ribosome biogenesis and protein translation by acting as RNA chaperones, stabilising rRNA and promoting the correct folding of transcribed proteins. These proteins also have extraribosomal functions associated with apoptosis, cell cycle arrest, proliferation and migration mediated by MDM2/ p53 dependent and p53-independent mechanisms (Xu et al. 2016). Ribosomal proteins furthermore play an important role in the maintenance of genomic integrity by modulating the DNA damage repair response (Xu et al. 2016). Their function has been mainly studied in the context of tumorigenesis where it has been shown that either impairment or hyperactivation of ribosomal biogenesis is associated with deregulated cell growth (Barna et al. 2008, Xu et al. 2016). Patterns of dysregulated ribosomal proteins are also thought to be predictive of disease progression in cancer and has highly specific effects on mRNA translation (Guimaraes \& Zavolan 2016). To our knowledge, this is the first study to identify dysregulated ribosomal proteins in chronic DM wounds and warrants further investigation, especially since the extra-ribosomal functions (i.e. DNA damage repair, proliferation, migration) are all processes known to be impaired in DM wounds. 
Initial stages proteins involved in cellular growth (Tpt1)

Consistent with the overexpression of ribosomal proteins, the growth-associated protein Tpt1 was also overexpressed more than two-fold in the DM wounds. Tpt1 is a cytoprotective protein known to promote cellular division/growth and plays a role in the oxidative stress response to either promote DNA damage repair or induce autophagy (Bommer 2017). In the context of DM, Tpt1 have been implicated in DM-associated dementia (Matsuura et al. 2018), nephropathy (Tessari et al. 2007) and the development of auto-immune DM (Yan et al. 2008), confirming its role in the pathogenesis of DM. Even though it has not been studied in the context of DM wounds, other proteomic studies have identified Tpt 1 as protein of interest in burn wounds (Pollins et al. 2007) and nerve regeneration (Jiménez et al. 2005), indicating that it might have a potential role in dysregulated healing responses.

In addition to the proteins discussed previously, this study also identified differentially expressed proteins involved in metabolic regulation/lipid rafts (FABP5, Cavin1), co-factors/catalases/protease inhibitors (Stfa1, Stfa3, Cycs, Tkt) and vestibular bodies (Chmp2a) during the initial stages postwounding. The role of these proteins in wound repair is unknown. It is, however, clear from the current data, that the protein dysregulation in DM wounds evident during the early stages (day 2) postwounding is complex and involve multiple regulatory pathways and biological processes.

\section{Late stage proteins involved in immune modulation (Cfd, Ptms, Hp), transcriptional regulation (Hmga1, Cbx3) and neural synapses (Syap1)}

In the later stages postwounding (day 7), fewer proteins were differentially expressed between acute and DM wounds compared to the initial stage. On day 7 postwounding, two immune modulatory proteins namely, complement factor D (Cfd) (also known as adipsin) and parathymosin (Ptms) were downregulated in DM wounds. Cfd is thought to be one of the links between energy metabolism and the innate immune response (White et al. 1992). It has a prominent role in lipid accumulation by mediating adipogenesis within WAT and simultaneously plays a role in the cleavage of C3 in the alternative immune complement pathway to induce inflammation (White et al. 1992, Song et al. 2016,
Vasilenko et al. 2017). Elevated serum Cfd levels have been detected in DM patients with retinopathy (Hase et al. 2017) and it has been implicated in age-associated deterioration of the dermal skin layer (Ezure et al. 2019). In the current study, Cfd was, however, downregulated in the DM wounds on day 7 postwounding. Similarly, Ptms known to inhibit the transcriptional activity of pro-inflammatory NFkB (Okamoto et al. 2016) was also downregulated in the DM wounds, whilst haptoglobin (Hp) which has anti-inflammatory properties (Krzyszczyk et al. 2020) was upregulated. Krzyszczyk et al. (2020) recently demonstrated that haptoglobin elicit strong anti-inflammatory effects (involving the downregulation of Hmga1 signalling) in LPS-stimulated macrophages in vitro and that $\mathrm{Hp}$ treatment of $\mathrm{DM}$ wounds ( $\mathrm{db} / \mathrm{db}$ mice) improved healing outcomes. Despite a similar profile (increased Hp and decreased Hmga1) being observed in the current study, there were no signs of healing in the DM wounds suggesting that cellular targets within the wounds might be unresponsive to signalling in this more severe wound model. The diverse regulation of different inflammatory mediators observed during the late stages of healing in this study further highlights the complexity of interactions between the underlying molecular processes in chronic wounds. In addition to these immune modulatory proteins of interest, Cbx3 and Syap1 was also diversely expressed in acute vs DM wounds on day 7, the role of these proteins in either DM or wound healing is, however, unknown.

\section{Conclusion}

This study highlighted the complex nature of obese DM wounds and suggest that early intervention immediately postinjury in high risk type $2 \mathrm{DM}$ patients should be considered. It furthermore identified numerous proteins that play a potential role in the development of chronic wounds. Future studies with more in-depth investigation are, however, required to determine cause-and-effect. Validation of the proteomic findings using antibodies to target proteins of interest overtime during wound healing is required in future studies using either Western blotting or immunohistochemistry. A further limitation of the current study was not being able to distinguish between the contribution of obesity and hyperglycaemia and the results are therefore only applicable to obesityassociated type 2 diabetic patients. Given the complexity of dysregulation, therapeutic agents targeting a single pathway is unlikely to be successful (as have been evident to date with the lack of effective treatments). Biological 
agents such as engineered mesenchymal stem cells or inflammatory cells (macrophages) that can 'sense' and restore the microenvironment through paracrine signalling and facilitate the transition into the proliferative phase of healing should be the focus of regenerative strategies.

\section{Declaration of interest}

The authors declare that there is no conflict of interest that could be perceived as prejudicing the impartiality of the research reported.

\section{Funding}

This study was supported by funding from the National Research Foundation (NRF) of South Africa and the Harry Crossley Foundation. K Boodhoo was supported by a bursary from the NRF. D L T was supported by the South African Tuberculosis Bioinformatics Initiative (SATBBI), a Strategic Health Innovation Partnership grant from the South African Medical Research Council and South African Department of Science and Technology.

\section{Data availability}

http://proteomecentral.proteomexchange.org/cgi/ GetDataset?ID=PXD020134

\section{Author contribution statement}

$\mathrm{K} \mathrm{B}$ performed all the experimental procedures on the animals, sample analysis and wrote the first draft of the manuscript. $M V$ assisted with sample preparation and performed the LC-MS/MS experiments. D L T did the quality control of mass spectrometry data and performed all the bioinformatic analysis. $\mathrm{K} \mathrm{H} \mathrm{M}$ contributed to the original study design and editing of the manuscript. $\mathrm{M} \vee \mathrm{d} \mathrm{V}$ contributed to the study design, data interpretation, statistical analysis and writing of the manuscript. All authors contributed to the editing of the final manuscript.

\section{References}

Alexiadou K \& Doupis J 2012 Management of diabetic foot ulcers. Diabetes Therapy 3 4. (https://doi.org/10.1007/s13300-012-0004-9)

Antezana M, Sullivan SR, Usui M, Gibran N, Spenny M, Larsen J, Ansel J, Bunnett N \& Olerud J 2002 Neutral endopeptidase activity is increased in the skin of subjects with diabetic ulcers. Journal of Investigative Dermatology 119 1400-1404. (https://doi. org/10.1046/j.1523-1747.2002.19618.x)

Bag S, Ramaiah S \& Anbarasu A 2015 fabp4 is central to eight obesity associated genes: a functional gene network-based polymorphic study. Journal of Theoretical Biology 364 344-354. (https://doi. org/10.1016/j.jtbi.2014.09.034)

Barna M, Pusic A, Zollo O, Costa M, Kondrashov N, Rego E, Rao PH \& Ruggero D 2008 Suppression of Myc oncogenic activity by ribosomal protein haploinsufficiency. Nature $\mathbf{4 5 6}$ 971-975. (https://doi. org/10.1038/nature07449)

Bommer UA 2017 The translational controlled tumour protein TCTP: biological functions and regulation. Results and Problems in Cell Differentiation 64 69-126. (https://doi.org/10.1007/978-3-31967591-6_4)
Chen CC, Chen N \& Lau LF 2001 The angiogenic factors Cyr61 and connective tissue growth factor induce adhesive signaling in primary human skin fibroblasts. Journal of Biological Chemistry 276 10443-10452. (https://doi.org/10.1074/jbc.M008087200)

Chen JS, Longaker MT \& Gurtner GC 2013 Murine models of human wound healing. Methods in Molecular Biology 1037 265-274. (https:// doi.org/10.1007/978-1-62703-505-7_15)

Cho NH, Shaw JE, Karuranga S, Huang Y, da Rocha Fernandes JD, Ohlrogge AW \& Malanda B 2018 IDF Diabetes Atlas: global estimates of diabetes prevalence for 2017 and projections for 2045. Diabetes Research and Clinical Practice 138 271-281. (https://doi.org/10.1016/j. diabres.2018.02.023)

da Silva L, Carvalho E \& Cruz MT 2010 Role of neuropeptides in skin inflammation and its involvement in diabetic wound healing. Expert Opinion on Biological Therapy 10 1427-1439. (https://doi.org/10.1517/ 14712598.2010.515207)

Desai D, Singh P, Van De Water L \& Laflamme SE 2013 Dynamic regulation of integrin $\alpha 6 \beta 4$ during angiogenesis: potential implications for pathogenic wound healing. Advances in Wound Care 2 401-409. (https://doi.org/10.1089/wound.2013.0455)

Dunn TN, Akiyama T, Lee HW, Kim JB, Knotts TA, Smith SR, Sears DD, Carstens E \& Adams SH 2015 Evaluation of the synuclein- $\gamma$ (SNCG) gene as a PPAR $\gamma$ target in murine adipocytes, dorsal root ganglia somatosensory neurons, and human adipose tissue. PLOS ONE $\mathbf{1 0}$ e0115830. (https://doi.org/10.1371/journal.pone.0115830)

Ezure T, Sugahara M \& Amano S 2019 Senescent dermal fibroblasts negatively influence fibroblast extracellular matrix-related gene expression partly via secretion of complement factor D. Biofactors $\mathbf{4 5}$ 556-562. (https://doi.org/10.1002/biof.1512)

Fadini GP, Menegazzo L, Rigato M, Scattolini V, Poncina N, Bruttocao A, Ciciliot S, Mammano F, Ciubotaru CD, Brocco E, et al. 2016 NETosis delays diabetic wound healing in mice and humans. Diabetes 65 1061-1071. (https://doi.org/10.2337/db15-0863)

Fortington LV, Geertzen JHB, van Netten JJ, Postema K, Rommers GM \& Dijkstra PU 2013 Short and long term mortality rates after a lower limb amputation. European Journal of Vascular and Endovascular Surgery 46 124-131. (https://doi.org/10.1016/j.ejvs.2013.03.024)

Frykberg RG \& Banks J 2015 Challenges in the treatment of chronic wounds. Advances in Wound Care 4 560-582. (https://doi. org/10.1089/wound.2015.0635)

Galeano M, Torre V, Deodato B, Campo GM, Colonna M, Sturiale A, Squadrito F, Cavallari V, Cucinotta D, Buemi M, et al. 2001 Raxofelast, a hydrophilic vitamin E-like antioxidant, stimulates wound healing in genetically diabetic mice. Surgery 129 467-477. (https://doi.org/10.1067/msy.2001.112072)

Ganesh GV \& Ramkumar KM 2020 Macrophage mediation in normal and diabetic wound healing responses. Inflammation Research 69 347-363. (https://doi.org/10.1007/s00011-020-01328-y)

Goh SY \& Cooper ME 2008 Clinical review: the role of advanced glycation end products in progression and complications of diabetes. Journal of Clinical Endocrinology and Metabolism 93 1143-1152. (https://doi.org/10.1210/jc.2007-1817)

Grose R, Hutter C, Bloch W, Thorey I, Watt FM, Fässler R, Brakebusch C \& Werner S 2002 A crucial role of beta 1 integrins for keratinocyte migration in vitro and during cutaneous wound repair. Development 129 2303-2315.

Guimaraes JC \& Zavolan M 2016 Patterns of ribosomal protein expression specify normal and malignant human cells. Genome Biology 17 236. (https://doi.org/10.1186/s13059-016-1104-z)

Guo G, Ren S, Kang Y, Liu Y, Duscher D, Machens HG \& Chen Z 2019 Microarray analyses of lncRNAs and mRNAs expression profiling associated with diabetic peripheral neuropathy in rats. Journal of Cellular Biochemistry 120 15347-15359. (https://doi.org/10.1002/jcb.28802)

Hase K, Kanda A, Hirose I, Noda K \& Ishida S 2017 Systemic factors related to soluble (pro)renin receptor in plasma of patients with 
proliferative diabetic retinopathy. PLOS ONE 12 e0189696. (https:// doi.org/10.1371/journal.pone.0189696)

Hsu CP, Moghadaszadeh B, Hartwig JH \& Beggs AH 2018 Sarcomeric and nonmuscle $\alpha$-actinin isoforms exhibit differential dynamics at skeletal muscle Z-lines. Cytoskeleton $\mathbf{7 5}$ 213-228. (https://doi. org $/ 10.1002 / \mathrm{cm} .21442)$

Jiménez CR, Stam FJ, Li KW, Gouwenberg Y, Hornshaw MP, De Winter F, Verhaagen J \& Smit AB 2005 Proteomics of the injured rat sciatic nerve reveals protein expression dynamics during regeneration. Molecular and Cellular Proteomics 4 120-132. (https://doi.org/10.1074/ mcp.M400076-MCP200)

Jin DK, Fish AJ, Wayner EA, Mauer M, Setty S, Tsilibary E \& Kim Y 1996 Distribution of integrin subunits in human diabetic kidneys. Journal of the American Society of Nephrology 7 2636-2645.

Jones JI, Nguyen TT, Peng Z \& Chang M 2019 Targeting MMP-9 in diabetic foot ulcers. Pharmaceuticals 12 79. (https://doi.org/10.3390/ ph12020079)

Jun JI \& Lau LF 2010 The matricellular protein CCN1 induces fibroblast senescence and restricts fibrosis in cutaneous wound healing. Nature Cell Biology 12 676-685. (https://doi.org/10.1038/ncb2070)

Jun JI \& Lau LF 2017 CCN2 induces cellular senescence in fibroblasts. Journal of Cell Communication and Signaling 11 15-23. (https://doi. org/10.1007/s12079-016-0359-1)

Kobayashi M, Ohno T, Ihara K, Murai A, Kumazawa M, Hoshino H, Iwanaga K, Iwai H, Hamana Y, Ito M, et al. 2014 Searching for genomic region of high-fat diet-induced type 2 diabetes in mouse chromosome 2 by analysis of congenic strains. PLoS ONE 9 e96271. (https://doi.org/10.1371/journal.pone.0096271)

Krzyszczyk P, Kang HJ, Kumar S, Meng Y, O'Reggio MD, Patel K, Pires IS, Yarmush ML, Schloss RS, Palmer AF, et al. 2020 Anti-inflammatory effects of haptoglobin on LPS-stimulated macrophages: role of HMGB1 signaling and implications in chronic wound healing. Wound Repair and Regeneration 28 493-505. (https://doi.org/10.1111/wrr.12814)

Landén NX, Li D \& Ståhle M 2016 Transition from inflammation to proliferation: a critical step during wound healing. Cellular and Molecular Life Sciences 73 3861-3885. (https://doi.org/10.1007/ s00018-016-2268-0)

Leal EC, Carvalho E, Tellechea A, Kafanas A, Tecilazich F, Kearney C, Kuchibhotla S, Auster ME, Kokkotou E, Mooney DJ, et al. 2015 Substance P promotes wound healing in diabetes by modulating inflammation and macrophage phenotype. American Journal of Pathology 185 1638-1648. (https://doi.org/10.1016/j. ajpath.2015.02.011)

Mason CC, Hanson RL, Ossowski V, Bian L, Baier LJ, Krakoff J \& Bogardus C 2011 Bimodal distribution of RNA expression levels in human skeletal muscle tissue. BMC Genomics 12 98. (https://doi. org/10.1186/1471-2164-12-98)

Matsuura K, Otani M, Takano M, Kadoyama K \& Matsuyama S 2018 Proteomic analysis of hippocampus and cortex in streptozotocininduced diabetic model mice showing dementia. Journal of Diabetes Research 2018 8953015. (https://doi.org/10.1155/2018/8953015)

Mercurio AM, Rabinovitz I \& Shaw LM 2001 The alpha 6 beta 4 integrin and epithelial cell migration. Current Opinion in Cell Biology 13 541-545. (https://doi.org/10.1016/s0955-0674(00)00249-0)

Millership S, Ninkina N, Guschina IA, Norton J, Brambilla R, Oort PJ, Adams SH, Dennis RJ, Voshol PJ, Rochford JJ, et al. 2012 Increased lipolysis and altered lipid homeostasis protect $\gamma$-synuclein-null mutant mice from diet-induced obesity. PNAS 109 20943-20948. (https://doi.org/10.1073/pnas.1210022110)

Mulder GD, Lee DK \& Jeppesen NS 2012 Comprehensive review of the clinical application of autologous mesenchymal stem cells in the treatment of chronic wounds and diabetic bone healing. International Wound Journal 9 595-600. (https://doi. org/10.1111/j.1742-481X.2011.00922.x)

O'Connor TM, O'Connell J, O'Brien DI, Goode T, Bredin CP \& Shanahan F 2004 The role of substance P in inflammatory disease.
Journal of Cellular Physiology 201 167-180. (https://doi.org/10.1002/ jcp.20061)

Okamoto K, Hirata-Tsuchiya S, Kitamura C, Omoteyama K, Sato T, Arito M, Kurokawa MS, Suematsu N \& Kato T 2016 A small nuclear acidic protein (MTI-II, Zn2+ binding protein, parathymosin) that inhibits transcriptional activity of NF- $\mathrm{kB}$ and its potential application to antiinflammatory drugs. Endocrinology 157 4973-4986. (https:// doi.org/10.1210/en.2016-1746)

Olerud JE, Usui ML, Seckin D, Chiu DS, Haycox CL, Song IS, Ansel JC \& Bunnett NW 1999 Neutral endopeptidase expression and distribution in human skin and wounds. Journal of Investigative Dermatology 112 873-881. (https://doi. org/10.1046/j.1523-1747.1999.00596.x)

Oort PJ, Knotts TA, Grino M, Naour N, Bastard JP, Clément K, Ninkina N, Buchman VL, Permana PA, Luo X, et al. 2008 Gammasynuclein is an adipocyte-neuron gene coordinately expressed with leptin and increased in human obesity. Journal of Nutrition $\mathbf{1 3 8}$ 841-848. (https://doi.org/10.1093/jn/138.5.841)

Ozgok Kangal MK \& Regan J-P 2020 Wound healing. In StatPearls. Treasure Island (FL): StatPearls Publishing. (https://www.ncbi.nlm. nih.gov/books/NBK535406/)

Pollins AC, Friedman DB \& Nanney LB 2007 Proteomic investigation of human burn wounds by 2D-difference gel electrophoresis and mass spectrometry. Journal of Surgical Research 142 143-152. (https://doi. org/10.1016/j.jss.2007.01.001)

Pradhan L, Nabzdyk C, Andersen ND, LoGerfo FW \& Veves A 2009 Inflammation and neuropeptides: the connection in diabetic wound healing. Expert Reviews in Molecular Medicine 11 e2. (https://doi. org/10.1017/S1462399409000945)

Robbins SG, Brem RB, Wilson DJ, O'Rourke LM, Robertson JE, Westra I, Planck SR \& Rosenbaum JT 1994 Immunolocalization of integrins in proliferative retinal membranes. Investigative Ophthalmology and Visual Science 35 3475-3485.

Sabino F, Egli FE, Savickas S, Holstein J, Kaspar D, Rollmann M, Kizhakkedathu JN, Pohlemann T, Smola H \& Auf dem Keller U 2018 Comparative degradomics of porcine and human wound exudates unravels biomarker candidates for assessment of wound healing progression in trauma patients. Journal of Investigative Dermatology 138 413-422. (https://doi.org/10.1016/j.jid.2017.08.032)

Sayers NM, Beswick LJ, Middlemas A, Calcutt NA, Mizisin AP, Tomlinson DR \& Fernyhough P 2003 Neurotrophin-3 prevents the proximal accumulation of neurofilament proteins in sensory neurons of streptozocin-induced diabetic rats. Diabetes 52 2372-2380. (https://doi.org/10.2337/diabetes.52.9.2372)

Schmohl M, Beckert S, Joos TO, Königsrainer A, Schneiderhan-Marra N \& Löffler MW 2012 Superficial wound swabbing: a novel method of sampling and processing wound fluid for subsequent immunoassay analysis in diabetic foot ulcerations. Diabetes Care 35 2113-2120. (https://doi.org/10.2337/dc11-2547)

Scott JR, Muangman PR, Tamura RN, Zhu KQ, Liang Z, Anthony J, Engrav LH \& Gibran NS 2005 Substance P levels and neutral endopeptidase activity in acute burn wounds and hypertrophic scar. Plastic and Reconstructive Surgery 115 1095-1102. (https://doi. org/10.1097/01.prs.0000156151.54042.da)

Scott JR, Muangman P \& Gibran NS 2007 Making sense of hypertrophic scar: a role for nerves. Wound Repair and Regeneration 15 (Supplement 1) S27-S31. (https://doi. org/10.1111/j.1524-475X.2007.00222.x)

Sen CK, Gordillo GM, Roy S, Kirsner R, Lambert L, Hunt TK, Gottrup F, Gurtner GC \& Longaker MT 2009 Human skin wounds: a major and snowballing threat to public health and the economy. Wound Repair and Regeneration 17 763-771. (https://doi. org/10.1111/j.1524-475X.2009.00543.x)

Seto JT, Lek M, Quinlan KGR, Houweling PJ, Zheng XF, Garton F, MacArthur DG, Raftery JM, Garvey SM, Hauser MA, et al. 2011 Deficiency of $\alpha$-actinin-3 is associated with increased susceptibility to https://jme.bioscientifica.com https://doi.org/10.1530/JME-20-0256 (c) 2021 Society for Endocrinology Published by Bioscientifica Ltd. Printed in Great Britain 
contraction-induced damage and skeletal muscle remodeling. Human Molecular Genetics 20 2914-2927. (https://doi.org/10.1093/hmg/ ddr196)

Singh VP, Bali A, Singh N \& Jaggi AS 2014 Advanced glycation end products and diabetic complications. Korean Journal of Physiology and Pharmacology 18 1-14. (https://doi.org/10.4196/kjpp.2014.18.1.1)

Song NJ, Kim S, Jang BH, Chang SH, Yun UJ, Park KM, Waki H, Li DY, Tontonoz P \& Park KW 2016 Small molecule-induced complement factor D (adipsin) promotes lipid accumulation and adipocyte differentiation. PLOS ONE 11 e0162228. (https://doi.org/10.1371/ journal.pone.0162228)

Spenny ML, Muangman P, Sullivan SR, Bunnett NW, Ansel JC, Olerud JE \& Gibran NS 2002 Neutral endopeptidase inhibition in diabetic wound repair. Wound Repair and Regeneration 10 295-301. (https:// doi.org/10.1046/j.1524-475x.2002.10504.x)

Steyaert A, Burssens P, Forsyth R \& Vanderstraeten G 2010 Qualitative analysis of substance P, NK1-receptor and nerve ingrowth in substance P-treated ruptured rat Achilles tendon. Acta Orthopaedica Belgica 76 387-395.

Tessari P, Puricelli L, Iori E, Arrigoni G, Vedovato M, James P, Coracina A \& Millioni R 2007 Altered chaperone and protein turnover regulators expression in cultured skin fibroblasts from type 1 diabetes mellitus with nephropathy. Journal of Proteome Research 6 976-986. (https:// doi.org/10.1021/pr060443n)

Trengove NJ, Stacey MC, MacAuley S, Bennett N, Gibson J, Burslem F, Murphy G \& Schultz G 1999 Analysis of the acute and chronic wound environments: the role of proteases and their inhibitors.
Wound Repair and Regeneration 7 442-452. (https://doi. org/10.1046/j.1524-475x.1999.00442.x)

Um J, Yu J, Dubon MJ \& Park KS 2016 Substance P and thiorphan synergically enhance angiogenesis in wound healing. Tissue Engineering and Regenerative Medicine 13 149-154. (https://doi. org/10.1007/s13770-016-9089-y)

Vasilenko MA, Kirienkova EV, Skuratovskaia DA, Zatolokin PA, Mironyuk NI \& Litvinova LS 2017 The role of production of adipsin and leptin in the development of insulin resistance in patients with abdominal obesity. Doklady: Biochemistry and Biophysics 475 271-276. (https://doi.org/10.1134/S160767291704010X)

White RT, Damm D, Hancock N, Rosen BS, Lowell BB, Usher P, Flier JS \& Spiegelman BM 1992 Human adipsin is identical to complement factor D and is expressed at high levels in adipose tissue. Journal of Biological Chemistry 267 9210-9213.

Xu X, Xiong X \& Sun Y 2016 The role of ribosomal proteins in the regulation of cell proliferation, tumorigenesis, and genomic integrity. Science China: Life Sciences 59 656-672. (https://doi.org/10.1007/ s11427-016-0018-0)

Yan Y, Xiong Z, Zhang S, Song J, Huang Y, Thornton AM, Wang H \& Yang XF 2008 CD25high T cells with a prolonged survival inhibit development of diabetes. International Journal of Immunopathology and Pharmacology 21 767-780. (https://doi. org/10.1177/039463200802100401)

Zhong J, Gong Q \& Mima A 2017 Inflammatory regulation in diabetes and metabolic dysfunction. Journal of Diabetes Research 2017 5165268. (https://doi.org/10.1155/2017/5165268)

Received in final form 3 November 2020

Accepted 16 December 2020

Accepted Manuscript published online 23 December 2020
(C) 2021 Society for Endocrinology Published by Bioscientifica Ltd. Printed in Great Britain 